\title{
Erratum to: Redescription and designation of a neotype for Aphthalmichthys kuro Kuroda 1947, and its placement in Callechelys (Anguilliformes: Ophichthidae)
}

John E. McCosker • Kiyotaka Hatooka •

Nobuhiro Ohnishi · Hiromitsu Endo

Published online: 29 July 2011

(C) The Ichthyological Society of Japan 2011

Erratum to: Ichthyol Res (2011) 58:272-277

DOI 10.1007/s10228-011-0233-3

The spelling of the fourth author name was incorrect.

The online version of the original article can be found under doi:10.1007/s10228-011-0233-3.

J. E. McCosker $(\square)$

California Academy of Sciences,

San Francisco, CA 94118, USA

e-mail: jmccosker@calacademy.org

K. Hatooka

Osaka Museum of Natural History, 1-23 Nagai Park,

Higashi-Sumiyoshi, Osaka 546-0034, Japan

e-mail: hatooka@mus-nh.city.osaka.jp

\section{N. Ohnishi}

Department of Bioenvironmental Design,

Kyoto Gakuen University, 1-1 Nanjyo Otani,

Sogabe-cho, Kameoka, Kyoto 621-8555, Japan

e-mail: ohnishin@kyotogakuen.ac.jp

\section{H. Endo}

Laboratory of Marine Biology, Faculty of Science,

Kochi University, 2-5-1 Akebono-cho,

Kochi 780-8520, Japan

e-mail: endoh@kochi-u.ac.jp 